\title{
Os Manuais Escolares na Gestão do Currículo de Matemática: que papel para o professor?
}

\author{
Textbooks in the Mathematics Curriculum Management: \\ what is the role for the teacher?
}

Floriano Viseu*

ORCID ID 0000-0002-8221-6870

José Carlos Morgado**

ORCID ID 0000-0002-1216-2264

\begin{abstract}
Resumo
O manual escolar é um instrumento de trabalho muito utilizado tanto pelos professores, como pelos alunos. Apesar das críticas a que é sujeito, sobretudo pelo impacto negativo que pode marcar a profissionalidade docente, o manual tem conseguido afirmar-se como importante auxiliar das práticas pedagógicas. Importa, por isso, averiguar de que modo o manual escolar é utilizado pelos professores de Matemática, procurando inferir se o utilizam como mero auxiliar didático ou se determina muito do trabalho que é realizado na e para a sala de aula. Os dados foram recolhidos através de entrevistas semiestruturadas e da observação não participante. A generalidade dos professores que participaram no estudo integra os manuais escolares tanto ao nível da preparação, como da concretização dos processos de ensino-aprendizagem. A maioria dos professores não recorre, com a frequência que seria desejável, a outros materiais didáticos, o que, para além de indiciar uma certa dependência do manual escolar, pode contribuir para a sua progressiva desprofissionalização.
\end{abstract}

Palavras-chave: Manuais Escolares. Práticas Pedagógicas. Decisões Curriculares. Profissionalidade Docente. Matemática.

\begin{abstract}
The textbook continues to be a working tool widely used in schools, both by teachers and students. Despite the criticism it is subject to, especially by the negative impact it can bring to teachers' professionalism, this teaching material has managed to be considered as an important auxiliary of pedagogical practices. It is vital, therefore, to ascertain how textbooks are used by math teachers, trying to infer whether they use it as mere teaching aid or if it determines much of the work performed in and for the classroom. The data was collected through semi-structured interviews and non-participant observation. It appears that the majority of the teachers who participated in the study include textbooks in their daily curricular activities, both in the preparation and the implementation of the teaching-learning processes. Most teachers don't use, as often as it would be desirable, other materials or educational sources, which, in addition to indicate a certain dependence of these teaching resources, can contribute to its progressive 'de-professionalization'.
\end{abstract}

Keywords: Textbooks. Pedagogical Practices. Curriculum Decisions. Teachers' Professionalism. Mathematics.

\footnotetext{
* Doutor em Educação, Especialidade de Didática da Matemática, pela Universidade de Lisboa (Ulisboa), Portugal. Professor Auxiliar no Instituto de Educação da Universidade do Minho (UMinho), Braga, Portugal. Endereço para correspondência: Campus de Gualtar, Braga, Portugal, CEP: 4710-057. E-mail: fviseu@ie.uminho.pt.

** Doutor em Educação, Especialidade de Desenvolvimento Curricular, pela Universidade do Minho (UMinho), Portugal. Professor Associado no Instituto de Educação da Universidade do Minho (UMinho), Braga, Portugal. Endereço para correspondência: Campus de Gualtar, Braga, Portugal, CEP: 4710-057. E-mail: jmorgado@ie.uminho.pt.
} 


\section{Introdução}

Vivemos um tempo especial em que a vertigem tecnológica se apossou do nosso quotidiano (CARNEIRO, 2003) e nos confronta com uma panóplia de recursos didáticos cada vez mais exuberantes e sofisticados, com destaque para os suportes informáticos e tecnológicos, hoje presentes em muitas das salas de aula. Um tempo complexo, pejado de turbulências e incertezas, refém da ideologia da novidade e no qual todos, sem exceção, enfrentamos o desafio de nos reorganizarmos "em função de ambientes cada vez mais inteligentes, polvilhados de entes cada vez mais interativos e ciosos de autonomia" (CARNEIRO, 2003, p. 11). Um tempo que, perante a torrente de informação que nos inunda e a renovação veloz do conhecimento, consigna à Educação um papel essencial, uma vez que a idealiza como ação promotora de valores, como esteio de cidadania, como espaço de partilha e como meio para apetrechar os indivíduos para a mudança e para a aprendizagem ao longo da vida. No fundo, um tempo de mudança do arquétipo escolar, em que o ensinar cede lugar ao aprender, colocando no centro da ação educativa o aprendente. Daí a necessidade de implementar modelos didáticopedagógicos que facilitem a aquisição, compreensão e transposição dos conhecimentos, pouco consonantes com a utilização intensiva de recursos preconcebidos, em detrimento de modelos que fazem da transmissão e da memorização os seus principais referentes (RAMOS, 2010).

Contudo, não deixa de ser surpreendente que, neste cenário de mudanças, o manual escolar $^{1}$ continue a ser um dos recursos didático-pedagógicos mais utilizados no quotidiano educativo, permitindo a Paulo (1999) afirmar que o manual escolar se configura "como algo tão natural quanto a escola" (p. 355).

De fato, apesar da diversidade de opiniões sobre as funções dos recursos didáticos e da profusão de suportes tecnológicos, os manuais escolares continuam a ser um recurso pedagógico por excelência, escolhidos em cada escola pelos respectivos professores, sendo os instrumentos didáticos mais utilizados, com impacto significativo nos processos de ensinoaprendizagem que aí se desenvolvem. Existem até professores que continuam a considerar que o manual escolar deve ser um meio de trabalho para utilizar diariamente, lendo e sublinhando sempre que necessário, ainda que tal prática contrarie as orientações emanadas, mais recentemente, pela tutela, no sentido da progressiva reutilização do manual escolar durante o

\footnotetext{
${ }^{1}$ Importa esclarecer que a expressão "manual escolar", vulgarmente utilizada em Portugal, é uma designação similar à de "livro didático", usada no Brasil. Trata-se de um recurso didático-pedagógico do processo de ensinoaprendizagem que, embora originalmente concebido para o aluno, pode também servir de apoio às atividades do professor.
} 
seu período de vigência.

A utilização frequente dos manuais escolares é comprovada por vários estudos, como, por exemplo, os realizados por Pepin, Gueudet e Trouche (2013), que confirmam essa predominância e demonstram que os manuais veiculam perspectivas oficiais expressas nos documentos curriculares e influenciam significativamente a forma como cada professor idealiza e concretiza essas perspectivas na aula de Matemática.

Usiskin (2013) ainda refere-se à utilização frequente dos manuais escolares de Matemática, apesar de considerar que nos encontramos perante uma clara evolução tecnológica, a que não é alheia à profusão de meios eletrônicos cada vez mais sofisticados que competem com os recursos didáticos mais tradicionais e que acabarão por ocupar um lugar cada vez mais proeminente nos processos de ensino-aprendizagem.

Esta previsão, e os benefícios que daí resultarão, são reforçados por Ruiz de Gauna, Dávila, Etxeberría e Sarasua (2013, p. 274), cujos estudos evidenciaram que, "com o advento dos livros digitais, em que a interação livro-aluno e a utilização de softwares dinâmicos no ensino de Matemática serão maiores, se verificará a implementação de processos educativos menos expositivos e mais próximos dos interesses dos alunos e da realidade em que se inserem".

Importa, por isso, averiguar o papel do manual escolar na configuração das práticas curriculares de professores de Matemática e verificar se os utilizam como meros auxiliares didáticos ou se, por circunstâncias diversas, são os manuais escolares que determinam muito do trabalho que é realizado na sala de aula.

Para o efeito, este texto encontra-se estruturado em cinco segmentos principais: o primeiro e o segundo relativos à fundamentação teórica ao longo da qual se faz referência à importância do manual escolar no quotidiano educativo e à sua integração na prática docente do professor de Matemática; o terceiro sobre a descrição do estudo e a metodologia de investigação utilizada; o quarto, dedicado à apresentação e discussão dos resultados; o quinto em que se sintetizam os principais aspectos conclusivos do trabalho e se identificam pistas de investigação futura.

\section{Importância do manual escolar no quotidiano educativo}

Atendendo aos modos como os manuais escolares têm sido descritos, verificamos que são múltiplos os ângulos de análise e as dimensões que cada autor privilegia. Todavia, existem pontos comuns que permitem constatar que, globalmente, estamos em presença de um livro, cuja relevância resulta das suas características especiais e de assumir funções específicas ao 
nível dos processos de ensino-aprendizagem que configuram o fenômeno educativo. A este respeito, Magalhães $(2006$, p. 8) considera que o manual escolar "simboliza uma construção cultural, estrutura o ato do conhecimento, materializa a relação pedagógica e configura o campo epistêmico-pedagógico da cultura escolar".

No caso deste estudo, limitamo-nos a referir que as principais vertentes comuns se circunscrevem às dimensões cultural, ideológica e pedagógica que, de forma mais ou menos explícita, qualquer manual corporiza e que são reconhecidas pela generalidade dos autores. No quadro da historiografia do manual escolar em Portugal, Magalhães $(2006$, p. 8) considera-o como "o principal meio de informação, conhecimento e legitimação da cultura escrita e da ação escolar", desempenhando uma importante função didático-pedagógica.

Respondendo às necessidades, prerrogativas e circunstâncias históricas da cultura escolar e da pedagogia, o autor considera que o manual, como produto cultural, escolar e pedagógico, orientado para um sujeito leitor, em processo de formação e de crescimento, e cuja atividade de leitura deverá ser orientada e dirigida para determinados fins, corporiza "uma pragmática que integra de forma articulada finalidades de diferente natureza e uma diversidade de facetas, quanto à morfologia e aos conteúdos" (MAGALHÃES, 2006, p. 8), aspectos que, em conjunto, lhe conferem singularidade própria.

Em idêntica linha de pensamento, Bonafe (2002) advoga que a preponderância que o manual escolar adquiriu resulta do fato de atuar como catalisador (oficial) do ensino e da aprendizagem e como um dispositivo que favorece a relação entre o saber e o poder na escola. Além disso, como estratégia discursiva, o manual atua como esteio de normalização institucional, vinculando cada indivíduo a uma identidade conhecida e predeterminada.

Concebido como forma de saber, como veículo de circulação legítima do saber e como meio de acesso ao saber, o manual escolar configura-se como um recurso didático-pedagógico e, em simultâneo, como um instrumento político-ideológico. Por isso, qualquer seleção cultural não pode ignorar as dimensões de natureza ideológica e política que lhe estão subjacentes, o que reforça a natureza ética e política do próprio ato educativo. É nesse sentido que Apple (2002, p. 66) assevera que a forma como se seleciona, organiza e apresenta o conhecimento curricular traduz "a visão de alguém a respeito do que se deve considerar legítimo em matéria de conhecimento e cultura" e atua como mecanismo de controle técnico das práticas de ensino.

$\mathrm{Na}$ verdade, a forma como se estruturam os materiais curriculares determina, direta ou indiretamente, grande parte das atividades de escolarização. Na perspectiva de Bonafe (1999), isso acontece porque os recursos didáticos corporizam, ao mesmo tempo: (i) um código de regulação pedagógica - que traduz uma forma específica de entender a seleção cultural, as 
tarefas pedagógicas dos professores e as aprendizagens dos estudantes; e (ii) um código de regulação social de significados culturais - que sintetiza uma forma de relação entre os subsistemas político, econômico e cultural de uma sociedade, no interior do seu sistema educativo.

Em nosso entender, a estes códigos se acresce um terceiro, que denominamos código de regulação profissional e que veicula um modelo de profissionalidade docente (MORGADO, 2004), aqui entendida como conjunto de conhecimentos, destrezas, atitudes e valores característicos da ação docente e que constituem a especificidade de ser professor (GIMENO, 1995).

Este código de regulação profissional interfere com o grau de autonomia que o professor detém, o papel que assume no campo das decisões curriculares, as orientações metodológicas que perfilha, as competências de investigação que desenvolve e a postura profissional que assume perante os alunos, a escola e a comunidade (MORGADO, 2004). Estes códigos, que dão forma e legitimam o conhecimento que a escola deve difundir, geram significados específicos relativo às práticas educativas, interferindo tanto nos processos de desenvolvimento profissional docente, como na manutenção ou alteração da racionalidade curricular que consubstancia os fenômenos educativos.

Estas questões merecem uma atenção particular se tivermos em conta, como sugere Alarcão (2001), que, em termos éticos e profissionais, cada docente tem obrigação de apoiar o seu trabalho em contínuos processos de investigação e reflexão, de interpelar as razões que sustentam a prática educativa que desenvolve na sala de aula e de olhar para os manuais escolares com sentido crítico, equacionando assim o seu papel, quer como profissional do currículo, quer como dinamizador de aprendizagens, tornando-se, por isso, um dos principais responsáveis pelo sucesso escolar dos alunos.

\section{Integração do manual escolar na prática docente do professor de Matemática}

Na mediação entre conhecimento matemático e alunos, o professor tem ao seu dispor manuais escolares que desempenham um papel fulcral na forma como planifica e dinamiza as aulas. A prevalência do manual escolar nas atividades que se desenvolvem na aula de Matemática tende a condicionar a organização dos conteúdos matemáticos e suas abordagens didáticas (MULLIS; MARTIN; FOY, 2008; PEPIN; GUEUDET; TROUCHE, 2013). Muitas vezes, a organização dos conteúdos resulta da sequência proposta no manual, não sendo alterada pelo professor, provavelmente porque é o instrumento que privilegia na sua ação didática 
(PEPIN; HAGGARTY, 2001; PEPIN; GUEUDET; TROUCHE, 2013). É neste sentido que Howson (2013) considera que os manuais escolares desempenham um precioso papel no desenvolvimento do currículo, fornecem aos professores um quadro conceitual para orientar o seu trabalho e interferem na forma como os conteúdos matemáticos são ensinados e consolidados através de atividades práticas, muitas delas sob a forma de exercícios.

Ora, quando o conteúdo matemático surge já tratado, como acontece na maior parte dos manuais, compete ao professor descodificar a informação a apresentar ao aluno. Se isso não acontece, o professor assume o papel de mero reprodutor de conhecimentos, tanto na forma como introduz os conceitos, como nas tarefas que seleciona.

Além disso, a reprodução da informação do manual tende a retirar do aluno a oportunidade de se envolver na (re)construção dessa informação (BALL; COHEN, 1996). É neste sentido que Fan, Zhu e Miao (2013) alertam para o caso específico da Matemática, em que a dependência do manual escolar é uma das características mais frequentes, destacando-se de outras disciplinas, ainda que considerem a capacidade dos manuais organizarem e sequenciarem de forma lógica os conteúdos e de introduzirem os estudantes em temas menos óbvios que não podem experimentar diretamente.

A prevalência do manual escolar na ação didática do professor de Matemática faz com que Pepin e Haggarty (2001) relacionem as formas de utilização deste artefato com distintas perspectivas de ensino da Matemática. Segundo estes autores, há uma diversidade de perspectivas sobre a natureza do ensino de Matemática, desde a aquisição de conhecimentos através de atividades desligadas entre si, até a aquisição de capacidades (por exemplo, de resolução de problemas, resolução de tarefas de exploração ou de investigação) que proporcionam o conhecimento de conteúdos.

Essas perspectivas transportam uma noção de manual escolar que reflete um determinado ponto de vista do ensino de Matemática, porque podem existir manuais com poucas conexões entre os diferentes conceitos matemáticos ou que incentivem o aluno a explorar e questionar e o estimulem a ser autônomo nas atividades de aprendizagem. O manual escolar tende, assim, a condicionar a pedagogia dos professores, transmitindo mensagens pedagógicas que podem encorajar ou desencorajar a dinamização de diferentes estratégias de ensino. Como temos vindo a aperceber através da nossa prática profissional, muitas vezes a justificação de falta de tempo leva os professores a valorizarem mais a produção de resultados do que a pensar matematicamente, partilhar significados e dinamizar o trabalho em grupo.

O modo como o manual escolar é integrado nas estratégias de ensino sem ser questionado pelo professor faz com que Gascón (2001) o compare ao método euclidiano. O 
conhecimento matemático pode deduzir-se de um conjunto finito de proposições trivialmente verdadeiras (axiomas), a partir de termos perfeitamente conhecidos (termos primitivos). A verdade dos axiomas flui até aos teoremas através de processos dedutivos de transmissão da verdade (provas), o que o autor denomina de trivialização do conhecimento matemático.

Esta forma de interpretar o saber matemático no sistema de ensino pode dar origem a dois modelos docentes, aparentemente distintos entre si, que têm em comum a trivialização do processo de ensino: o teorismo e o tecnicismo. Trata-se de duas formas de materializar modelos docentes, segundo os quais o processo de ensino é necessário e trivial, totalmente controlado pelo professor. O envolvimento do aluno nas atividades da aula é pouco valorizado, emergindo atividades mecânicas, repetitivas, de transmissão de conceitos e de procedimentos sem significado.

Os docentes que integram o modelo teorista perfilham uma concepção de saber matemático que enfatiza os conhecimentos acabados e cristalizados em teorias, tendo em consideração o produto final da atividade, sem se importar com a atividade matemática desenvolvida. Quando no ensino predomina o teorismo, dá-se importância ao momento em que os alunos contactam, pela primeira vez, com os objetos matemáticos através da sua apresentação pelo professor, mediante processos de transmissão de conhecimentos cristalizados numa teoria.

Perante esta prática, Gascón (2001) considera que o processo didático termina no momento em que o professor apresenta aos alunos essa teoria. Dado que, nesta perspectiva, ensinar Matemática é divulgar teorias, o ensino-aprendizagem transforma-se num processo trivial. Mas a prática contradiz essa trivialidade e torna-se um paradoxo nas instituições onde predomina o teorismo. Nesses casos, é muito difícil debelar as dificuldades que os alunos têm para utilizar adequadamente um teorema, aplicar uma técnica matemática, comprovar se um objeto matemático cumpre ou não os pressupostos de uma definição e resolver problemas. A resolução de problemas é considerada uma atividade secundária, cuja função é auxiliar a aprendizagem de teorias. Os problemas servem, essencialmente, para aplicar, exemplificar ou consolidar conceitos teóricos. O teorismo ignora as tarefas destinadas a elaborar estratégias de resolução de problemas complexos. Quando aparece um problema que não pode resolver-se através da aplicação imediata de um resultado matemático, então o teorismo decompõe-no em exercícios rotineiros. O envolvimento do aluno é nulo na elaboração de definições. Esta teoria ignora os processos da atividade matemática, não concedendo qualquer importância ao desenvolvimento do conhecimento matemático.

A realização de uma atividade a partir da teoria faz emergir o domínio de técnicas 
matemáticas (modelo tecnicista), que só ganham sentido quando a teoria é compreendida. No modelo tecnicista, ensinar e aprender Matemática significa ensinar e aprender técnicas. $\mathrm{O}$ tecnicismo tende a ignorar os problemas que levantem dificuldades na escolha das técnicas adequadas para construir uma estratégia de resolução. O tecnicismo reparte com o teorismo um certo tipo de trivialização da atividade de resolução de problemas: parte-se de certas técnicas algorítmicas e propõem-se, unicamente, problemas/exercícios que sirvam de entretenimento para chegar a dominá-las, excluindo as estratégias de resolução complexas e não algorítmicas.

Em ambos os modelos concebe-se o processo de ensino como algo mecânico e trivial, totalmente controlado pelo professor. $\mathrm{O}$ teorismo tende a conceber o aluno como uma caixa vazia para ser preenchida durante um processo gradual, que parte de conceitos mais simples até chegar, passo a passo, aos sistemas conceituais mais complexos. O tecnicismo considera o aluno como um autômato que melhora o domínio das técnicas mediante a repetição, o que proporciona uma formação aprofundada.

A convicção de que tanto a origem do conhecimento como o método matemático, e inclusive a sua justificação, provêm da experiência faz fracassar a perspectiva euclidiana. $\mathrm{O}$ que justifica uma teoria matemática não é o fato de os axiomas serem verdadeiros, nem sequer que não sejam contraditórios, mas permitirem deduzir resultados essenciais.

Davis e Hersh (1995), baseando-se na filosofia da dúvida de Lakatos, propõem as teorias quase-empiristas em contraposição às euclidianas. Uma teoria euclidiana é verdadeira na medida em que se apoia em enunciados básicos verdadeiros (axiomas), enquanto numa teoria quase-empirista os enunciados básicos verdadeiros (que não são axiomas) são simplesmente explicados pelo resto do sistema, que formam um todo coerente, não contraditório. As teorias matemáticas em fase de desenvolvimento são informais, sendo esta etapa em que se levantam os problemas mais interessantes (que abordam novos conceitos, promovem o questionamento e induzem a diferenciação dos conceitos anteriores). O modelo quase-empirista provoca a destrivialização do conhecimento matemático ao enfatizar o papel do processo de descoberta e destaca (em contraposição ao modelo euclidiano) que a análise de tal conhecimento não pode reduzir-se ao mero estudo da justificação das teorias matemáticas.

No desenvolvimento do conhecimento matemático valoriza-se a atividade, como a resolução de problemas não triviais e de tarefas sobre as quais não se sabe grande coisa sobre o processo de resolução. Isto significa que o modelo quase-empirista identifica a atividade de ensinar e aprender Matemática como atividade exploratória, livre e criativa, de problemas não triviais, cujos enunciados não sugerem procedimentos de resolução. Assim se compreende que se o professor se limitar a seguir o manual escolar o processo exploratório pode ficar 
inviabilizado, prevalecendo a lógica de reprodução.

\section{Metodologia de investigação}

Para averiguar o papel do manual escolar na configuração das práticas curriculares de professores de Matemática, em particular na forma como utilizam este recurso, realizamos um estudo com professores que lecionaram essa disciplina no Ensino Básico e Secundário, em duas escolas públicas no distrito de Braga, em Portugal, que, por questão de anonimato, designamos como Escola Secundária A (ESA) e Escola Secundária B (ESB). É sobre as etapas do estudo, a metodologia utilizada e os resultados obtidos que versa o próximo segmento do texto.

\subsection{Problemática e objetivos da investigação}

Como referimos na introdução, a principal finalidade deste estudo incide no modo como os manuais são utilizados pelo professor de Matemática e que efeitos daí resultam, quer em termos da aprendizagem dos alunos, quer ao nível do desenvolvimento profissional docente. Com o intuito de nortear o percurso investigativo referido, delinearam-se os seguintes objetivos específicos: (1) conhecer a frequência de utilização do manual escolar na sala de aula; (2) identificar modos de utilização do manual escolar dentro e fora da sala de aula; (3) compreender a relação entre o manual e o desenvolvimento profissional docente.

\subsection{Opções metodológicas e intervenientes no estudo}

Em termos metodológicos optou-se por uma abordagem de cariz interpretativo, uma vez que pretendíamos compreender os significados que os professores consignam às ações didáticopedagógicas que desenvolvem (LESSARD-HÉBERT; GOYETTE; BOUTIN, 1990). A opção pela abordagem interpretativa, centrada no significado que os indivíduos dão aos fenômenos, deve-se, segundo Erickson (1986, p. 119), ao interesse pelo "significado humano da vida social e na sua clarificação e exposição por parte do investigador".

Participaram neste estudo nove professores que lecionavam em turmas do $9 .^{\circ}$ e do $12 .^{\circ}$ ano de escolaridade das ESA e ESB. A opção por circunscrever o estudo a estes anos de escolaridade resultou do fato de serem anos terminais do Ensino Básico e do Ensino 
Secundário $^{2}$ e, por essa razão, estarem sujeitos a exame nacional.

Uma vez que o estudo se baseava na análise das práticas de ensino-aprendizagem na sala de aula, tivemos o cuidado de incluir docentes que cumprissem as seguintes condições: (a) fossem portadores de habilitação profissional, garantindo assim que possuíam formação científica e pedagógica adequada ao exercício da docência; (b) tivessem, no mínimo, cinco anos efetivos de serviço docente, o que permitiu trabalhar com docentes com experiência letiva e assegurar que o estudo evidenciasse o que se passa no contexto da sala de aula. A maioria dos professores intervenientes no estudo, a quem atribuímos um nome fictício, tem mais de 10 anos de serviço:

Tabela 1 - Tempo de serviço docente dos professores

\begin{tabular}{|c|c|c|c|}
\hline & & Nome do Professor & Anos de serviço \\
\hline \multirow{5}{*}{ 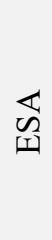 } & \multirow{2}{*}{$\ddot{\sigma}$} & Fernando & 8 \\
\hline & & Patrícia & 11 \\
\hline & \multirow{3}{*}{$\stackrel{\circ}{\stackrel{\sim}{\sim}}$} & João & 17 \\
\hline & & Teresa & 19 \\
\hline & & Rosa & 21 \\
\hline \multirow{4}{*}{$\begin{array}{l}\mathscr{n} \\
\text { صు }\end{array}$} & $\stackrel{\circ}{\circ}$ & Sônia & 11 \\
\hline & \multirow{3}{*}{$\stackrel{\circ}{\check{I}}$} & Maria & 22 \\
\hline & & Manuel & 25 \\
\hline & & Gil & 30 \\
\hline
\end{tabular}

Fonte: Elaborada pelos autores (2015).

Entre os professores que participaram no estudo, cinco pertenciam ao quadro da ESA dois lecionavam nas turmas do $9 .^{\circ}$ ano de escolaridade e três nas do $12 .^{\circ}$ ano - , e quatro ao quadro da ESB - um que lecionava na única turma de $9 .^{\circ}$ ano que existia nessa escola e três professores que lecionavam nas turmas do $12 .^{\circ}$ ano.

\subsection{Técnicas de recolha e de análise de dados}

Tendo em conta que pretendíamos verificar como é que os professores integram os manuais escolares nas práticas curriculares que desenvolvem na escola, para recolher os dados optamos por realizar entrevistas semiestruturadas e observações não participantes. Dada "a natureza essencialmente prática dos fenómenos educativos, bem como a complexidade, o

\footnotetext{
${ }^{2} \mathrm{O}$ sistema de ensino português engloba 12 anos antes da entrada no Ensino Superior. Desses anos, os primeiros nove correspondem ao Ensino Básico e os três últimos ao Ensino Secundário. No Ensino Básico, constituído por três ciclos - o primeiro de quatro anos, o segundo de dois anos e o terceiro ciclo de três anos -, o currículo da disciplina de Matemática é igual para todos os alunos. Nos três anos de Ensino Secundário, em que os alunos começam a ser encaminhados para um grupo de cursos do Ensino Superior, os currículos da disciplina de Matemática divergem, consoante seguem cursos de Ciências, Humanísticos, Tecnológicos ou Artes.
} 
dinamismo e a interatividade que caraterizam a vida nas aulas", um estudo deste teor requer que as práticas investigativas no terreno se pautem por alguma prudência e recorram a técnicas metodológicas abertas e flexíveis (MORGADO, 2003, p. 331). Daí a escolha das técnicas referidas e dos instrumentos utilizados - Grelha de Observação de Aula (Anexo 1) e Guião da Entrevista (Anexo 2) -, tendo sido, nas duas situações, especificamente elaborados para o efeito.

Além dos aspectos referidos, existiram ainda outros motivos que estiveram na base das nossas opções e que importam referir. No caso da entrevista, o fato de, para além de permitir conhecer mais profundamente a opinião dos entrevistados e de ter associada a possibilidade de, como reitera Angulo (1987, p. 23), permite identificar os "significados que permanecem implícitos no pensamento dos professores" e, consequentemente, "compreender os sentidos e os significados que atribuem às suas ações".

No caso da observação não participante, pesou o fato de ser uma técnica de recolha que, embora exija uma boa capacidade de concentração por parte do investigador, permite "selecionar um pequeno número de informações pertinentes de entre o vasto leque de informações possíveis" (DE KETELE; ROEGIERS, 1996, p. 23).

Apesar de ser uma técnica que se nutre de procedimentos mais intrusivos do que outras, o que pode ter inconvenientes, a observação não participante teve a vantagem de permitir contextualizar opiniões, atitudes e comportamentos dos professores que participaram no estudo. De cada um dos nove professores que colaboraram no estudo, foram observadas três aulas, o que perfaz um total de nove aulas observadas dos professores do $9 .^{\circ}$ ano e dezoito dos professores do $12 .^{\circ}$ ano.

Ao longo das observações, e dado que tínhamos optado pela observação não participante, limitamo-nos a registrar os aspectos que consideramos necessários, de acordo com as categorias predefinidas. Nesse sentido, recolhemos evidências que nos permitiram identificar o protagonismo dos diferentes intervenientes no processo de ensino-aprendizagem, o tipo de informação e de conteúdos veiculados nas aulas e o modelo pedagógico subjacente a todo esse processo.

Na aplicação de cada técnica tivemos alguns cuidados especiais, sobretudo por termos desenvolvido uma abordagem de cariz qualitativo. Sendo uma abordagem que requer a intrusão no contexto onde decorre o estudo, é essencial que o investigador "entre no mundo do sujeito" procurando, em simultâneo, manter-se "do lado de fora" (BOGDAN; BIKLEN, 1994, p. 113), o que só será possível se conseguir ser empático e reflexivo, mantendo-se, ao mesmo tempo, suficientemente distanciado para discernir com lucidez as situações que observa. Trata-se de 
um exercício difícil, que se realizou da melhor forma possível, uma vez que, como lembram Bogdan e Biklen (1994), exige que o investigador aprenda o modo de pensar do sujeito, mas não pense como ele.

Com a informação recolhida, seguiu-se a análise de conteúdo com a finalidade de obter conhecimento e de o tornar compreensível a outros (BOGDAN; BIKLEN, 1994). Independentemente das técnicas utilizadas, é sempre determinante a criatividade do investigador, na forma como dá sentido aos dados que interpreta, tendo em consideração o esquema conceitual em torno do qual se baseia o enquadramento teórico do estudo (PATTON, 1990).

Nessa análise, procurou-se identificar regularidades em torno da utilização do manual na prática letiva dos professores e das suas percepções sobre essa utilização, que se circunscreveram às categorias que a seguir se apresentam e que, segundo Miles e Huberman (1994), permitem ordenar, organizar e sistematizar a informação: (i) Frequência da utilização do manual nas aulas; (ii) Modos de utilização do manual escolar; (iii) Influência do manual escolar no desenvolvimento profissional docente.

A descrição da informação recolhida inclui citações dos participantes, permitindo ao leitor apreender, mais de perto, os acontecimentos e os contextos (GALL; GALL; BORG, 2007) em que o estudo se realizou. Dá-se, assim, oportunidade ao leitor de validar as inferências efetuadas, sustentando a credibilidade do estudo. Durante o processo de análise de dados houve a preocupação de não "acrescentar significados ou comentários à mensagem original, nem alterar o sentido da mensagem" (LESSARD-HÉBERT; GOYETTE; BOUTIN, 1990, p. 110). Além disso, procurou-se que a informação proveniente da fragmentação efetuada fosse compreensível quando lida fora do contexto em que está inserida (GALL; GALL; BORG, 2007).

\section{Apresentação e discussão dos resultados}

Uma vez que a recolha de dados foi feita com base quer na utilização que os professores faziam do manual escolar durante as aulas, quer da forma como o integravam na sua prática letiva e dos tipos de trabalhos propostos aos alunos, por questões de sistematicidade decidiu-se apresentar e discutir a informação recolhida de acordo com as categorias predefinidas, sem prejuízo de, no segmento seguinte, se tecerem algumas considerações finais sobre o estudo.

\subsection{Frequência de utilização do manual nas aulas}


Para analisar a frequência de utilização do manual escolar nas aulas decidiu-se organizar a informação recolhida em três subcategorias: utilização frequente; utilização moderada; e utilização esporádica ${ }^{3}$.

Os dados recolhidos nas turmas do $9 .^{\circ}$ ano permitiram constatar que dois dos professores que participaram no estudo fazem uma utilização frequente do manual escolar, isto é, estruturam as atividades realizadas com base nesse artefato. O outro professor faz uma utilização moderada do manual, uma vez que recorre a outro tipo de recursos, tais como fichas de trabalho com tarefas selecionadas especificamente para o efeito. A frequência com que estes professores utilizam o manual nas suas aulas deve-se, sobretudo, ao aproveitamento das tarefas que disponibiliza para a sistematização dos conhecimentos adquiridos, como ilustram as suas afirmações:

Utilizo sempre o manual escolar em todas as aulas. Raramente mando o aluno ler o manual uma vez que deve ser o professor a explicar os conteúdos que ai existem. O manual para os alunos é, essencialmente, para resolver exercícios. (...) Fora da aula, recorro a manuais escolares uma vez que facilitam a planificação das aulas.

(Entrevista com Patrícia, 9. ${ }^{\circ}$ ESA, 2015).

Utilizo frequentemente o manual escolar porque permite ver o tipo de exercícios que se enquadram na matéria que pretendo dar, fazer alguns exercícios durante a aula e marcar trabalho de casa.

(Entrevista com Fernando, 9. ${ }^{\circ}$, ESA, 2015).

O manual escolar é importante porque é um recurso que os alunos têm sempre disponível. Não utilizo apenas o manual escolar durante as aulas. Utilizo outros recursos que ajudam a complementá-lo e a diversificar o trabalho. Refiro-me, especificamente, a fichas de trabalho e a propostas de exercícios retirados de outros livros.

(Entrevista com Sônia, 9. ${ }^{\circ}$, ESB, 2015).

Para além da sistematização de conhecimentos, essencial na concretização da componente prática das aulas, a professora Sônia recorre a outros instrumentos com o intuito de diversificar o tipo de tarefas que integra nas suas estratégias de ensino.

Situação análoga, ainda que mais expressiva, passa-se ao nível do $12 .^{\circ}$ ano de escolaridade. Nas aulas observadas verificou-se que nenhum dos docentes utilizava de forma esporádica os manuais escolares. Aliás, dos seis professores observados, cinco deles utilizavam de forma frequente o manual escolar, dentro e fora da sala de aula. O professor que utilizava o manual de forma mais moderada fazia-o porque recorria a outros manuais escolares e a fichas

\footnotetext{
${ }^{3}$ Utilização frequente: quando o professor estrutura quase todas as atividades da aula a partir do manual; utilização moderada: quando o professor utiliza de forma idêntica o manual e outros recursos didáticos nas aulas; utilização esporádica: quando prevalece a utilização de outros recursos didáticos sendo o manual escolar utilizado apenas pontualmente.
} 
de trabalho elaboradas anteriormente.

Recorro frequentemente ao manual tanto para preparar as aulas, como para expor os conteúdos aos alunos. O manual adotado nesta escola está tão bem construído, praticamente não necessito recorrer a outras fontes. Quando elaboro testes, procuro noutros manuais exercícios tipo dos exames nacionais.

(Entrevista com Rosa, 12. ${ }^{\circ}$, ESA, 2015).

Acho importante a utilização do manual porque tem a informação essencial. Além disso, é informação concentrada e organizada de acordo com o programa. Para além da abordagem dos conteúdos ser mais fácil, privilegio a parte dos exercícios porque os alunos precisam trabalhar muito para adquirir ritmo e desenvolver algumas competências.

(Entrevista com Gil, 12. ${ }^{\circ}$ ano, ESB, 2015).

Utilizo o manual escolar, mas não só para resolução de exercícios. Em matemática a prática é indispensável para um bom desempenho. (...) Procuro utilizar outros manuais, exames nacionais de anos anteriores e fichas de trabalho que elaboro para os alunos. Em termos teóricos, incentivo os alunos a procurarem outras fontes de informação que ajudem ao estudo dos conteúdos.

(Entrevista com Maria, 12. ${ }^{\circ}$ ano, ESB, 2015).

As afirmações apresentadas permitem-nos verificar alguma dependência dos docentes inquiridos relativamente ao manual escolar. Uma situação que os docentes justificam com base na fidelidade do manual ao programa oficial da disciplina, desvalorizando os efeitos nefastos que daí resultam. Quando os docentes se eximem dessa dependência assumem maior protagonismo no processo de ensino-aprendizagem. A este respeito as afirmações de um dos professores são reveladoras: "sigo o manual porque serve de orientação ao programa, quando não segue eu salto e faço a alteração que tiver que fazer. Até costumo ditar exercícios para os alunos resolverem" (Entrevista com Manuel, 12. ${ }^{\circ}$ ano, ESB, 2015).

Em suma, a análise dos dados relativos à frequência com que os professores utilizam o manual escolar nas aulas permite constatar que, para além do manual ser um recurso pedagógico por excelência, tendem a emergir duas concepções, ainda que complementares, sobre o ensino de Matemática: a que valoriza a atividade do professor, sobretudo nos momentos de explanação dos conceitos matemáticos, e a que considera essencial a participação do aluno na construção desse conhecimento. Foi com base nas concepções emergentes durante o estudo que decidimos verificar como é que os professores utilizam os manuais nas aulas.

\subsection{Modos de utilização do manual escolar}

Na segunda categoria de análise, procuramos averiguar se o protagonismo atribuído ao manual interferia, ou não, com o papel desempenhado pelo professor e pelo aluno nas aulas. Verificamos que, tanto ao nível do $9 .^{\circ}$ como do $12 .^{\circ}$ ano de escolaridade, o manual escolar 
ocupava um lugar central na aprendizagem dos estudantes. Quando o manual perdia relevância, a atenção transferia-se para a figura do professor, uma situação mais marcante nos momentos de introdução de novas temáticas. Em todo este processo, o aluno foi sendo relegado para o papel de mero executante daquilo que outros decidiam.

Este fato acabou por condicionar as estratégias didáticas utilizadas nas aulas, o tipo de atividades realizadas e a postura assumida pelos professores. Ao nível das atividades não deixa de ser sintomática a prevalência de atividades de resolução de exercícios e de alguns problemas, em detrimento de outras mais divergentes, mas não menos importantes, tais como as atividades de investigação e/ou de exploração. Além disso, verificou-se que o trabalho desenvolvido nas aulas decorreu numa perspectiva mais individualista, ainda que complementada com o recurso a outras modalidades, tais como o trabalho entre pares e, mais esporadicamente, o trabalho de grupo.

Na sequência da observação das práticas dos professores, que permitiu compreender as cadências de utilização dos manuais escolares, consideramos essencial averiguar que motivos estavam na base dos modos como os mesmos eram utilizados nas aulas. Relativamente aos professores do $9 .^{\circ}$ ano, essa utilização evidencia a preocupação de instruir os conteúdos programáticos pela ordem como aparecem no manual, de abordar as definições tal como aí são expressas e, sobretudo, de resolver as tarefas que o integram:

Tenho a preocupação de abordar os conteúdos de acordo com a sequência do manual, o que facilita a aprendizagem dos alunos.

(Entrevista com Patrícia, 9. ${ }^{\circ}$ ESA, 2015).

Procuro não recorrer a definições diferentes em relação ao manual. Na aula a utilização do livro é para resolver os exercícios que selecionei na fase de preparação da aula.

(Fernando, 9. ${ }^{\circ}$, ESA, 2015).

As partes que exploro mais do manual são os exercícios e, por vezes, as sinteses de conteúdos porque ajudam os alunos a organizar o pensamento e a assimilar determinados conceitos.

(Entrevista com Sônia, 9. ${ }^{\circ}$, ESB, 2015).

Quer através das entrevistas quer das observações das aulas, verificamos que poucos são os professores que recorrem ao manual escolar para interpelar o aluno e lhe dar oportunidade de cooperar consigo na construção do conhecimento matemático. Excetua-se o caso da Patrícia, cujas práticas letivas não se restringem à exposição de assuntos e consequente realização de exercícios. Com alguma frequência, a professora envolve os alunos em atividades de leitura, incita-os a relacionarem aspectos teóricos e gráficos e incentiva-os a selecionarem a informação mais importante do manual:

Por vezes, no início, quando estou a introduzir uma matéria ponho os alunos a ler o que está no manual e a tirar conclusões. Recorro ao manual essencialmente para resolver exercícios. 
Fora da aula, utilizo o manual como preparação da aula, em complemento com outros manuais, e para os alunos fazerem os trabalhos de casa. Se for uma aula em que os alunos tenham de analisar gráficos, lemos em conjunto a teoria e analisamos os gráficos. Deixo os alunos lerem, mas de vez em quando paro para os questionar e ver se estão a perceber. Considero que o livro de Matemática é para ler e sublinhar. Eu costumo dizer-lhes que devem utilizar e riscar como outro livro qualquer de outra disciplina, porque eles ligam mais só aos exercícios.

(Entrevista com Patrícia, 9. ${ }^{\circ}$, ESA, 2015).

No caso dos professores do $12 .^{\circ}$ ano, a qualidade do manual escolar determina em grande parte, ou inviabiliza, a sua utilização ou de outros manuais no desenvolvimento do currículo. Alguns professores socorrem-se de outros manuais para delinearem as metodologias a utilizar na abordagem dos conteúdos matemáticos, o que, por um lado, nos leva a supor que viabiliza o enriquecimento de aspectos do conhecimento didático do professor e, por outro, que tal enriquecimento favorece a melhoria e inovação das suas práticas curriculares. Porém, mesmo recorrendo a outras fontes de informação, existem professores que continuam a evidenciar uma concepção de ensino que supervaloriza a transmissão de informação, a explanação da teoria a partir da figura do professor e a utilização do manual como um recurso exclusivo para a resolução de exercícios:

Utilizo-o quando faço a exposição teórica de conteúdos na sala de aula e quando quero que os alunos façam exercícios do livro em casa.

(Entrevista com Teresa, 12.. , ESA, 2015).

Todos os dias usamos o manual, mais para a resolução de exercícios do que propriamente para a parte teórica. Quando se inicia um capítulo, leio vários manuais e faço uma pesquisa de várias fontes para ficar com uma ideia de como será a melhor forma de introduzir aquele conceito.

(Entrevista com João, 12. ${ }^{\circ}$, ESA, 2015).

O que valorizo no manual são os exercícios e a forma como expõe a teoria, um bom manual deve equilibrar a teoria e a prática.

(Entrevista com Gil, 12..$^{\circ}$ ano, ESB, 2015).

As seções do manual a que mais recorro são as que têm exercicios propostos, primeiro os mais simples depois os mais complexos, porque permite a todos os alunos interiorizar mais facilmente e aplicar a matéria dada. A seção que utilizo menos é a da autoavaliação proposta no final de cada capitulo porque o tempo não chega para fazer tudo.

(Entrevista com Maria, 12. ${ }^{\circ}$ ESB, 2015).

Os dados recolhidos permitem-nos inferir que a forma como o aluno explora o manual escolar se relaciona, significativamente, com os métodos de trabalho que o professor utiliza. Ao perceber, com base nos dados, que ao longo do seu percurso escolar o que registra no caderno é, muitas vezes, o que está no manual, o aluno tende a construir a ideia de que não vale a pena explorar no manual aquilo que tem no caderno. Dessa forma se compreende que muito do que os alunos fazem em termos de utilização do manual escolar remeta para a reprodução das atividades que o professor realiza. 
Assim, os resultados obtidos permitem concluir que estamos em presença de um processo de desenvolvimento do currículo alheio a qualquer tentativa de ampliar e/ou enriquecer aquilo que é proposto a nível programático. Não seria mais profícuo para os alunos que os professores estruturassem o ensino-aprendizagem da Matemática numa lógica de projeto, favorecedora não só da articulação de saberes oriundos de diferentes áreas, mas também do desenvolvimento de capacidades de pesquisa, análise e reflexão?

\subsection{Influência do manual escolar no desenvolvimento profissional docente}

Ao veicular uma cultura específica, de natureza disciplinar, que tem subjacente uma dada filosofia de ensino (BONAFE, 2002), o manual escolar pode ser um elemento inibidor ou potenciador do desenvolvimento profissional docente. $\mathrm{O}$ primeiro efeito é mais frequente quando os professores recorrem continuamente ao manual escolar, cingindo a sua atuação a propostas de atividades de aprendizagem idealizadas por outros a partir do currículo prescrito. Quando isso acontece, predomina a inalterabilidade das práticas e criam-se condições para a eventual desprofissionalização docente.

Todavia, a utilização do manual pode, pelo contrário, ser um elemento potenciador do desenvolvimento profissional dos professores. Para isso, basta que o considerem apenas como mais um recurso pedagógico que têm à sua disposição. Esta situação é facilitada quando os professores trabalham de forma colaborativa com os colegas, confrontando ideias, aprofundando os seus conhecimentos pedagógico-didáticos e elaborando materiais em conjunto.

No caso dos professores de Matemática que integraram este estudo, a utilização do manual escolar surgiu sempre associada a práticas de cariz mais individualista, o que parece ficar a dever-se não só à visão de educação e ensino que possuem, mas também à (sobre)carga horária que lhes está atribuída, às crescentes solicitações profissionais com que se deparam e ao aumento de tarefas que lhes têm sido consignadas, o que lhes retira bastante tempo, dificultando assim o trabalho com os pares. Algumas destas razões são apontadas como justificativas da valorização que alguns fazem do manual, em detrimento da obrigação de construírem os materiais que utilizam nas aulas:

A dsiponibilidade de trabalhar na escola com os colegas é cada vez menor, o que faz com que não haja tempo para explorar materiais e elaborar estratégias de ensino de conceitos matemáticos.

(Entrevista com Maria, 12. $\left.{ }^{\circ}, \mathrm{ESB}, 2015\right)$.

Para o professor é benéfico que haja o manual como material de base para o seu trabalho. Se 
não tivessemos acesso a manuais, teríamos que criar sebentas que servissem de orientação das nossas aulas.

(Entrevista com Rosa, 12. ${ }^{\circ}$, ESA, 2015).

Importa referir que, embora os manuais sejam recursos idealizados, essencialmente, para apoiar o trabalho dos alunos, isso não deve impedir que sejam utilizados pelos professores e que a sua utilização incentive o trabalho conjunto no seio da classe docente, em particular na planificação das atividades a desenvolver ao longo do ano escolar e na definição de projetos de aprendizagem com caráter globalizante, que envolvam diferentes disciplinas.

No entanto, na prática, o manual escolar, ao servir de guia - quase exclusivo - do trabalho do professor, tem contribuído para que alguns se acomodem e se limitem a seguir as indicações aí emanadas, abrindo mão da tarefa de planificar e decidir as suas próprias práticas pedagógicas, uma responsabilidade que, por direito próprio, lhes está consignada. A esse respeito, as palavras de um dos professores inquiridos são sintomáticas:

O manual favorece a atividade do professor na preparação de aulas e na sua lecionação. Se não tivesse manuais escolares teria mais trabalho na elaboração de exercícios para os alunos praticarem.

(Entrevista com Fernando, 9. ${ }^{\circ}$, ESA, 2015).

As ideias explanadas consubstanciam uma forma de estar e ver a profissão docente em que os manuais escolares, mais do que um recurso didático, funcionam como um fim em si mesmo, acabando por se assumirem como mecanismos de controle técnico das práticas de ensino.

No entanto, existem professores que percebem que o trabalho com os pares e a experiência que adquirem através da exploração dos manuais podem ser determinantes no desenvolvimento da sua profissionalidade:

Quando iniciei as minhas funções na atual escola onde trabalho sentia-me presa ao manual, aos programas, não sabia muito bem se devia seguir o manual ou os programas. Com a experiência, sinto que já tenho capacidade de selecionar o que pretendo dinamizar com os alunos e para alterar a ordem dos capitulos sem perder a sua ligação. Para o desenvolvimento desta capacidade muito contribui o trabalho entre colegas.

(Entrevista com Patrícia, 9. ${ }^{\circ}$, ESA, 2015).

De fato, o trabalho colaborativo, ao permitir o confronto de saberes em relação a conteúdos matemáticos, a formas pedagógicas de os tornar compreensíveis para os alunos e a diferentes modos de gestão curricular, promove a partilha e estimula o crescimento profissional. Alguns professores vão mais longe ao sugerirem que a elaboração do manual na própria escola seria uma forma de responsabilizar o professor pela construção dos seus próprios materiais de trabalho e de o envolver em termos de decisão curricular:

O manual é dispensável, mas para isso era necessário elaborar um trabalho a nível do grupo 
disciplinar. No fundo, seria criar um manual próprio da escola e que estivesse de acordo com o programa.

(Entrevista com Sônia, 9. ${ }^{\circ}$, ESB, 2015).

O professor não se deve isolar em termos de trabalho, o trabalho cooperativo é fundamental, porque nós estamos sempre a aprender como professores e como pessoas. Dai a importância da partilha de experiências. Muitas vezes pensamos que uma estratégia está muito bem definida, mas depois de a confrontarmos com outros, acabamos por ir por outro caminho. O manual deveria ser um livro de consulta. O professor, com a ajuda dos colegas da mesma escola, devia desenvolver um conjunto de tarefas para os temas a abordar. Isso tornaria o trabalho mais perfeito numa escola: definir as atividades, os objetivos e construir os materiais em conjunto. A forma de abordar um determinado assunto, se pretender levar os alunos a desenvolver competências, deve ser feito numa lógica de trabalho reflexivo. Para isso, devia ser definido um conjunto de materiais que pudessem ser utilizados por todos os professores, depois de existir consenso entre eles. O trabalho de um professor não se esgota com meia dúzia de anos a trabalhar os programas; é necessário ensinar e aprender simultaneamente e remodelar sempre que possivel, mas sempre numa base de um trabalho cooperativo.

(Entrevista com Fernando, 9. ${ }^{\circ}$ ESA, 2015).

Existem professores que não se acomodam a uma postura reprodutora e investem numa efetiva (re)construção e/ou transformação do currículo, concebendo a sua ação como profissionais autônomos que gerem a sua atividade em função dos diálogos com os pares, com os diferentes intervenientes do processo educativo e de acordo com a realidade escolar que enquadra a sua atividade. Quando isso acontece, os professores exibem uma clara maturidade curricular e não ficam reféns de qualquer recurso didático, assumindo-se, por isso, como decisores das suas práticas, dentro e fora da sala de aula. Nesses casos, os manuais escolares são reconhecidos como um recurso valioso para o seu desenvolvimento profissional, cumprindo cabalmente a função para a qual foram concebidos.

\section{Conclusões}

Em jeito de conclusão, importa salientar três aspectos essenciais e que, em nosso entender, condicionam o papel desempenhado pelos professores de Matemática, isto é, a sua profissionalidade.

Desde logo, o fato dos manuais escolares serem recursos didáticos que interferem no modo como se organizam, implementam e avaliam os processos de ensino-aprendizagem. No caso em apreço, verifica-se que a maioria dos professores que participaram no estudo se revelou utilizadora frequente do manual, o que determina aquilo que trabalham nas aulas e afeta a sua autonomia curricular. O manual escolar revelou-se um material didático onipresente quer nos momentos de preparação/planificação das atividades letivas, quer na sequencialização e abordagem dos conteúdos nas aulas. 
Tais práticas indiciam, como refere Zabalza (1992), que o manual escolar, além de fonte exclusiva na fase da preparação das aulas, substitui o papel do programa prescrito pela tutela na consulta e interpretação das orientações emanadas por este artefato curricular. Já na abordagem dos conteúdos, os professores tendem a orientar as aulas através da sequência do manual, o que para Gimeno (1988) lhes dá uma maior segurança no desenvolvimento da sua ação educativa. Na perspectiva de Remillard (1999), a dependência que o manual escolar gera na prática do professor não favorece a adaptação do currículo às características dos alunos, nem proporciona oportunidades de abordar os conteúdos por processos diferentes dos apresentados nos manuais e de inovar a prática docente.

A propósito da necessidade de recorrer a processos diferentes, não deixa de ser curioso, como demonstram os estudos de Esteves (2006) e Martinha (2011), que mesmo em momentos de reorganização curricular de âmbito nacional, como os que se viveram recentemente em Portugal, em que se pretende aligeirar o peso do currículo e adotar um novo modelo de ensinoaprendizagem, as editoras emagreçam os manuais ao nível dos conteúdos propostos, mas compensem essa dieta com a sugestão de mais atividades, sem terem a preocupação de, em idêntica medida, essas atividades incorporarem questões desafiantes que promovam o recurso a outras fontes e o desenvolvimento de competências nos estudantes.

Em segundo lugar, o modo como o manual foi utilizado nas aulas. Neste domínio, os resultados revelaram-se preocupantes, uma vez que se constatou que o manual escolar ocupava um lugar central na aprendizagem dos estudantes. Mais preocupante ainda foi verificar que sempre que o manual escolar perdia relevância, ela se transferia para a figura do professor, relegando o estudante para posição menor. Neste caso, os manuais acabam por funcionar como correias transmissoras do currículo oficial e por enclausurar a aprendizagem dos estudantes na redoma da memorização.

Assim se confirma, como Morgado (2003) demonstrou em estudo similar, que, na maioria dos casos, os manuais escolares não se afirmam como meios de interpelação de saberes, limitando-se à mera transmissão de conhecimentos, acadêmica e institucionalmente reconhecidos como válidos. Uma situação que permite afirmar modelos de ensino que valorizam a centralidade do professor, o que, segundo Gascón (2001), se reflete na reprodução dos factos e procedimentos matemáticos tal como são contemplados no manual. A diversidade de tarefas com diferentes características fica limitada aos exercícios e à resolução de problemas similares aos exames nacionais de fim de ciclo de escolaridade. O objetivo é a preparação para o exame, o que tem repercussões na atividade que o aluno realiza. Os exercícios de resolução divergente dão lugar a tarefas cujas resoluções e resultados não adquirem grau de 
imprevisibilidade, produzindo o que Gascón (2001) denomina trivialização do ensino.

A proposta de atividades de aprendizagem que promovam atitudes e capacidades, para além dos conhecimentos a adquirir, é desvalorizada, o que remete para uma concepção da Matemática como uma ciência fechada, não intuitiva e sem conexão entre os entes matemáticos que são estudados nos diferentes temas programáticos. Ora, o manual escolar pode ser uma fonte de experiências de aprendizagem mais significativas, se propuser tarefas que sejam exploradas com diversos materiais didáticos, tais como, por exemplo, os softwares dinâmicos e a calculadora gráfica. Com artefatos didáticos deste tipo, o aluno pode se envolver em atividades que o impelem a pesquisar, errar, conjecturar, justificar e a provar resultados matemáticos que obtenha.

Por fim, a influência do manual escolar no desenvolvimento profissional docente. No caso dos professores com que trabalhamos, a frequência com que utilizam o manual e o modo como o fazem permitem-nos inferir que o manual escolar se revela como um recurso de grande potencial desprofissionalizante que, mais cedo ou mais tarde, poderá corroer a sua autonomia profissional.

Ao deixarem que o manual decida os objetivos a concretizar, os conteúdos a trabalhar e as atividades a realizar, os professores abrem mão da tarefa de planificar e da possibilidade de decidirem as suas práticas pedagógicas, alheiam-se das responsabilidades profissionais que devem assumir e refugiam-se em modelos de ensino ancorados em perspectivas mais tecnicistas. Ora, o manual escolar, como auxiliar do processo de ensino-aprendizagem, não deve ocupar um papel dominante nesse processo. Compete ao professor manter-se atento e desenvolver as ações necessárias para que a sua autonomia profissional não seja hipotecada. Daí a necessidade de recorrer a outras fontes e de elaborar materiais curriculares que sustentem a sua atividade profissional, eximindo-se, assim, da dependência dos manuais instituídos e aprovados.

Em suma, a decisão mais preponderante será sempre do professor, uma vez que dele depende a possibilidade de contrariar toda esta situação.

Para isso ser possível, basta que trabalhe com o programa da disciplina que leciona, se aproprie dos processos de mudança e os transforme em práticas concretas, e que o manual escolar seja apenas um dos recursos didáticos que utiliza, não o único, nem o principal. Isso será facilitado se trabalhar esses aspectos com os colegas. Caso contrário, acabará por se subordinar ao estipulado no manual escolar e, mais cedo ou mais tarde, por entrar numa rota progressiva de desprofissionalização. 


\section{Referências bibliográficas}

ALARCÃO, I. Professor-investigador: Que sentido? Que formação? In B. P. Campos (Ed.), Formação Profissional de Professores no Ensino Superior (Vol. 1, p. 21-31). Porto: Porto Editora, 2001.

ANGULO, L. V. Evaluación diagnóstica de los procesos mentales de los profesores. Sevilla: Publicaciones de la Universidad de Sevilla, 1987.

APPLE, M. EI conocimiento oficial. La educación democrática en una era conservadora. Barcelona: Paidós, 2002.

BALL, D. L.; COHEN, D. K. Reform by the book: What is-or might be- the role of curriculum materials in teacher learning and instructional reform? Educational Researcher, Washington, v. 25, $\mathrm{n}$. 9, p. 6-8, 1996.

BOGDAN, R.; BIKLEN, S. Investigação qualitativa em educação. Uma introdução à teoria e aos métodos. Porto: Porto Editora, 1994.

BONAFE, J. M. Trabajar en la escuela. Profesorado e reformas en el umbral del siglo XXI. Buenos Aires/Madrid: Miño y Dávila Editores, 1999.

BONAFE, J. M. Políticas del libro de texto escolar. Madrid: Morata, 2002.

CARNEIRO, R. Fundamentos da Educação e da Aprendizagem: 21 ensaios para o século 21. Vila Nova de Gaia: Fundação Manuel Leão, 2003.

DAVIS, P. J.; HERSH, R. A experiência matemática. Lisboa: Gradiva, 1995.

DE KETELE, J-M.; ROEGIERS, X. Méthodologie du recueil d'informations. Paris: De Boeck Université, 1996.

ERICKSON, F. Qualitative methods in research on teaching. In: WITTROCK, M. (Ed.). Handbook of Research on Teaching. New York: Macmillan, 1986. p. 119-161.

ESTEVES, M. H. Ensinar a "Cidade” no Ensino Básico. Finisterra, Lisboa, v. XLI, n. 81, p. 205-213, 2006.

FAN, L.; ZHU, Y.; MIAO, Z. Textbook research in mathematics education: development status and directions. Zentralblatt for the Didactics of Mathematics, Berlin, v. 45, p. 633-646, 2013.

GALL, M. D.; GALL, J. P.; BORG, W. R. Educational research: an introduction. 8. ed. Boston: Allyn and Bacon, 2007.

GASCÓN, J. Incidencia del modelo epistemológico de las matemáticas sobre las prácticas docentes. Revista Latinoamericana de Investigación en Matemática Educativa, Ciudad de México, v. 4, n. 2, p. 129-159, 2001.

GIMENO, J. El curriculum: una reflexión sobre la práctica. Madrid: Ed. Morata, 1988.

GIMENO, J. Consciência a acção sobre a prática como libertação profissional dos professores. In: NÓVOA, A. (Org.). Profissão Professor. Porto: Porto Editora, 1995. p. 63-92.

HOWSON, G. The development of mathematics textbooks: historical reflections from a personal perspective. Zentralblatt for the Didactics of Mathematics, Berlin, v. 45, p. 647-658, 2013.

LESSARD-HÉBERT, M.; GOYETTE, G.; BOUTIN, G. Investigação qualitativa: Fundamentos e práticas. Lisboa: Instituto Piaget, 1990. 
MAGALHÃES, J. O Manual Escolar no Quadro da História Cultural: para uma historiografia do manual escolar em Portugal. Sísifo. Revista de Ciências da Educação, Lisboa, v. 1, p. 5-14, 2006.

MARTINHA, C. Os manuais escolares e o desenvolvimento de competências nos alunos - um desafio de investigação. In: DUARTE, J. B. (Org.). Manuais Escolares: mudanças nos discursos e nas práticas. Lisboa: Edições Lusófonas, 2011. p. 9-22.

MILES, M. B.; HUBERMAN, A. M. Qualitative data analysis: an expanded sourcebook. Thousand Oaks: Sage, 1994.

MORGADO, J. C. Processos e Práticas de (Re)Construção da Autonomia Curricular. 2003. 840f. Tese (Doutoramento em Ciências de Educação) - Instituto de Educação, Universidade do Minho, 2003.

MORGADO, J. C. Manuais Escolares. Contributo para uma análise. Porto: Porto Editora, 2004.

MULLIS, I. V. S.; MARTIN, M. O.; FOY, P. TIMSS 2007 International Mathematics Report: Findings from IEA's Trends in International Mathematics and Science Study at the Fourth and Eighth Grades. Chestnut Hill, MA: TIMSS \& PIRLS International Study Center, Lynch School of Education, Boston College, 2008.

PATTON, M. Qualitative evaluation and research methods. 2. ed. Newbury Park, CA: Sage, 1990.

PAULO, J. C. "A Ensinar como um mestre". Manuais e organização da cultura escolar em perspectiva histórica. In: CASTRO, R. et al. (Orgs.). Manuais escolares. Estatuto, Funções, História. Braga: Universidade do Minho, 1999, p. 355-366.

PEPIN, B.; HAGGARTY, L. Mathematics textbooks and their use in English, French and German classrooms: a way to understand teaching and learning cultures. Zentralblatt for the Didactics of Mathematics, Berlin, v. 33, n. 5, p. 158-175, 2001.

PEPIN, B.; GUEUDET, G.; TROUCHE, L. Investigating textbooks as crucial interfaces between culture, policy and teacher curricular practice: two contrasted cases studies in France and Norway. Zentralblatt for the Didactics of Mathematics, Berlin, v. 45, p. 685-698, 2013.

RAMOS, K. M. Profissionalidade docente universitária: um conceito em (re) construção. Ensino emRevista, Uberlândia, v. 17, n. 2, p. 561-578, 2010.

REMILLARD, J. T. Curriculum materials in mathematics education reform: a framework for examining teachers' curriculum development. Curriculum Inquiry, Toronto, v. 29, n. 3, p. 315-342, 1999.

RUIZ DE GAUNA, J. et al. Los libros de texto de Matemáticas del Bachillerato en el periodo 1970 2005. Revista Latinoamericana de Investigación en Matemática Educativa, Ciudad de México, v. 16, n. 2, p. 245-276, 2013.

USISKIN, Z. Studying textbooks in an information age - a United States perspective. Zentralblatt for the Didactics of Mathematics, Berlin, v. 45, p. 713-723, 2013.

ZABALZA, M. Planificação e desenvolvimento curricular na escola. Rio Tinto: Edições Asa, 1992.

Submetido em 16 de Janeiro de 2018. Aprovado em 19 de Maio de 2018. 


\section{Anexos}

Assunto:

\section{Anexo1: Grelha de observação de Aula}

Utiliza várias vezes o manual ao longo da aula?

$\bigcirc$ De uma a três vezes

$O$ De quatro a seis

Mais de seis vezes

Em que situações usa o manual?

Introdução teórica de um conteúdo

Utilizar uma imagem, um gráfico, tabela, esquema

Consultar a seção "Nota Histórica"

O Fazer sínteses dos assuntos a abordar e/ou abordados

$\bigcirc$ Analisar/discutir definições, regras, propriedades...

$\bigcirc$ Resolver exercícios

O Realização de tarefas propostas na seção "Atividades"

O Realização de tarefas propostas na seção "Praticar"

$\bigcirc$ Resolução de Problemas

$\bigcirc$ Realização de trabalhos de grupo

Realização de trabalhos de pares

Realização de trabalhos individuais

Como articula o manual escolar com outros materiais didáticos?

$\bigcirc$ Com fichas de trabalho elaboradas pelo próprio professor e/ou grupo disciplinar

$\bigcirc$ Com tarefas selecionadas pelo professor

Com atividades realizadas no computador/calculadora gráfica $\mathrm{O}$

Incentiva os alunos a usarem o manual em casa?

\begin{tabular}{l|l}
$\bigcirc$ Sim & Observações: \\
Não & \\
\hline
\end{tabular}

Se a resposta foi afirmativa, de que forma o faz?

$\bigcirc$ Leitura de um conteúdo e/ou tema como introdução ou reforço Observações:

do estudo

Consultar a seção "Nota Histórica"

Fazer sínteses dos assuntos a abordar e/ou abordados

$\bigcirc$ Analisar/discutir definições, regras, propriedades...

Resolver exercícios

O Realização de tarefas propostas na secção "Atividades"

Realização de tarefas propostas na secção "Praticar"

$\bigcirc$ Resolução de Problemas

Realização de trabalhos de grupo

Realização de trabalhos de pares

$\bigcirc$ Realização de trabalhos individuais 


\section{Anexo2: Guião da Entrevista}

1. Como, quando e para quê utiliza o manual escolar, adotado pela escola na sua disciplina, na aula e fora dela?

2. O manual é uma mais-valia na orientação do trabalho de um professor nas aprendizagens e gestão das suas aulas? Por quê?

3. Acha pertinente ou dispensável a adoção de um manual, uma vez que existe um programa da disciplina, definido pelo Ministério da Educação, para o desenvolvimento e/ou gestão das suas aulas?

4. Os conteúdos a serem lecionados deverão ser elaborados pelo professor e/ou pelos professores do grupo disciplinar da escola? Por quê?

5. Considera que o manual deveria existir apenas como instrumento de estudo para o aluno e o professor deveria criar e/ou desenvolver os seus materiais de trabalho?

6. Quais as seções do manual adotado para a sua disciplina que mais utiliza? Por quê? E as que utiliza menos? Por quê?

7. Quais são os aspectos que mais valoriza num manual? Por quê?

8. Quando seleciona tarefas para as suas aulas costuma usar sobretudo as do manual adotado? Por que sim ou por que não?

9. Quando e por que é que procura outros materiais?

10. Quais são as funções do manual escolar?

11. Na sua prática letiva, procura seguir as orientações metodológicas e a sequência apresentada no manual para preparar as suas aulas? Por quê?

12. Considera que o manual escolar incentiva o uso diversificado de materiais? E de tarefas? Dê algum exemplo.

13. A existência de um manual condiciona as práticas letivas ao definir conteúdos e metodologias?

14. De que modo estimula os seus alunos a usar o manual escolar fora da sala de aula? 